\title{
ESTRATÉGIA E COMPETITIVIDADE: UM ESTUDO MULTICASO DA EDUCAÇÃO SUPERIOR PRIVADA BRASILEIRA
}

\section{STRATEGY AND COMPETITIVENESS: A MULTICASE STUDY OF BRAZILIAN PRIVATE HIGHER EDUCATION}

\section{ESTRATEGIA Y COMPETITIVIDAD: UN ESTUDIO MULTI CASO DE LA EDUCACIÓN UNIVERSITARIA PRIVADA BRASILEÑA}

\author{
Ricardo Viana Carvalho de Paiva \\ Professor do Programa de Mestrado Profissional em Administração - Centro Universitário UNA, Brasil. \\ Doutor em Administração pela Universidade Federal de Minas Gerais (UFMG, Brasil). \\ Endereço: Rua Aimorés, 1451, Bairro Lourdes, CEP 30140-071 , Belo Horizonte, MG ,Brasil \\ Telefone: (31) 3614-4105 \\ E-mail: ricardovcp@animaeducacao.com.br

\section{Danilo de Melo Costa} \\ Professor do Centro Universitário de Belo Horizonte/MG - Uni-BH. \\ Doutorando em Administração pela Universidade Federal de Minas Gerais (UFMG, Brasil) \\ Endereço: Avenida Antônio Carlos, 6627 , Pampulha, CEP 31270-901 , Belo Horizonte, MG - Brasil \\ Telefone: (31) 3409-5000 \\ E-mail: danilo_mcosta@yahoo.com.br
}

\section{Francisco Vidal Barbosa}

Professor Associado da Universidade Federal de Minas Gerais, Brasil Doutor em Competitividade Empresarial pela Aston University, Inglaterra

Endereço: Avenida Antônio Carlos, 6627 , Pampulha, CEP 31270-901, Belo Horizonte, MG - Brasil Telefone: (31) 3409-5000

E-mail: fvberlim@gmail.com

\section{Mário Teixeira Reis Neto}

Professor do Programa de Mestrado e Doutorado em Administração da Universidade FUMEC Doutor em Administração pela Universidade Federal de Minas Gerais (UFMG, Brasil).

Endereço: Av. Afondo Pena 3880, Cruzeiro, 1o andar, CEP 30310-009, Belo Horizonte, MG - Brasil Telefone: (31) 3280-9100

E-mail: reisnetomario@fumec.br

Artigo recebido em 18/01/2014. Revisado por pares em 13/03/2014. Reformulado em 04/08/2014. Recomendado para publicação em 25/11/2014 por Ademar Dutra (Editor Científico). Publicado em 30/12/2014. Avaliado pelo Sistema double blind review.
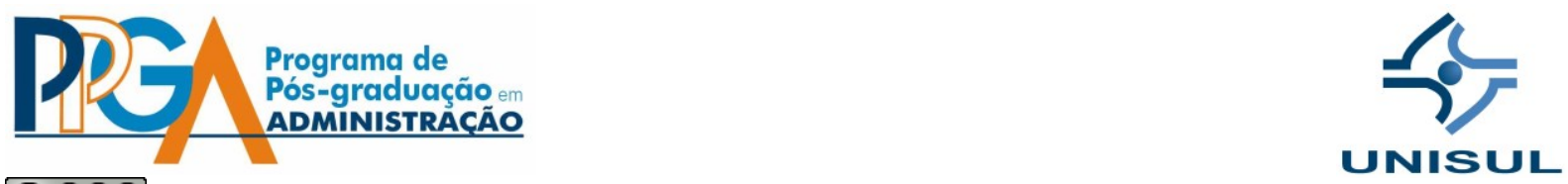
RESUMO

O presente trabalho propõe-se a realizar um estudo multicaso da avaliação das capacidades e recursos estratégicos de sete instituições privadas de ensino superior no Brasil. Para tanto, foi realizado um estudo exploratório, de caráter qualitativo, por meio de coleta documental de dados, bibliográfica e entrevista com gestores de sete instituições de ensino superior privadas, nacionalmente reconhecidas. Os resultados demonstraram que há uma tendência da formação e crescimento de grandes grupos educacionais, mas estes grupos também enfrentam vários desafios, possuindo desvantagens competitivas que devem ser observadas, sinalizando a necessidade de inovação no setor. Os dados coletados e tratados das entrevistas evidenciaram que a escolha das estratégias corretas representa um importante divisor de águas para se garantir o sucesso em um cenário cada vez mais exigente e competitivo, listando uma série de características que podem ajudar na construção de um olhar difuso da educação superior privada no Brasil.

Palavras-chave: Competitividade; Estratégia; Capacitações; Educação Superior Privada.

\section{ABSTRACT}

This paper proposes to conduct a multi case study of the evaluation of the capabilities and strategic resources of seven private institutions of higher education in Brazil. For this, we conducted an exploratory study of qualitative nature, by means of documental and bibliographic data collection, and interviews with managers from seven private higher education institutions nationally recognized. The results showed there is a tendency of the formation and growth of large educational groups but these groups also face various challenges, with competitive disadvantages that must be observed, indicating the need for innovation in the sector. The data collected and processed of the interviews showed that the choice of the correct strategies represent an important turning point to ensure success in a scenario increasingly demanding and competitive, listing a number of features that can help in building a diffused look of private higher education in Brazil.

Keywords: Competitiveness; Strategy; Capabilities; Private Higher Education.

\section{RESUMEN}

Este trabajo se propone a realizar un estudio multicaso de evaluación de las capacidades y recursos estratégicos de siete instituciones privadas de educación superior en Brasil. Para tanto fue realizado un estudio exploratorio, de carácter cualitativo, por medio de la colección documental de datos, bibliográfica y entrevista con gestores de siete instituciones de educación superior privadas, nacionalmente reconocidas. Los resultados demostraran que hay una tendencia de formación y crecimiento de grandes grupos educacionales, pero estos grupos también enfrentan varios desafíos, muestreando desventajas competitivas que deben ser observadas, señalizando la necesidad de innovación en el sector. Los datos recogidos y tratados de las entrevistas evidenciaran que la elección de las estrategias correctas representa un importante divisor de aguas para garantizar el suceso en un escenario cada vez más exigente y competitivo, listando una serie de características que poden ayudar en la construcción de una mirada difusa de la educación superior privada en Brasil.

Palabras-clave: Competitividad; Estrategia; Capacitaciones; Educación Superior Privada. 


\section{INTRODUÇÃo}

Nas últimas décadas, a educação superior tornou-se objeto de anseio para boa parte das famílias brasileiras, uma vez que passou a ser enxergada como o caminho mais certo de destaque social. Este movimento fez com que o seguimento entrasse em evidência, não só nas esfera pública, detentora do maior número de vagas inicialmente, como também na esfera privada, que começava a dar seus primeiros passos (década de 60).

Observando esta necessidade, o Estado realizou um investimento inicial para criação de várias universidades públicas, tanto de âmbito federal quanto de âmbito estadual e municipal. Adicionalmente, passou também a investir mais na capacitação técnica, através da criação de vários Centros Federais de Educação Tecnológica (CEFETs) e escolas técnicas profissionalizantes (que foram posteriormente reorganizadas em Instituto Federal de Educação, Ciência e Tecnologia (IFET's), como uma ação do Plano de Desenvolvimento da Educação). Os referidos investimentos foram responsáveis pela criação de praticamente todas as vagas na educação superior até a década de 70, mas ainda não absorviam toda a demanda da sociedade. Pelo motivo de limitação de verba e crises enfrentadas na época, o favorecimento pelo ensino privado foi a alternativa estudada e implantada (GERMANO, 1993).

A partir de então, o movimento gerou um grande crescimento das instituições de ensino superior privadas durante a década de 70 , que inverteram o cenário e passaram a deter a maioria das vagas disponíveis. Por outro lado, o crescimento acelerado e meramente quantitativo começou a trazer severos impactos na qualidade, o que fez com que o governo federal optasse por não autorizar o funcionamento de novas instituições privadas. Este momento perdurou até o ano de 1996, quando foi promulgada a Lei de Diretrizes e Bases (LDB/96). Por facilitar a criação de novas faculdades e centros universitários, houve uma expansão quase desenfreada, chegando a um cenário em que a oferta passou a ser bem maior do que a procura (MEYER JUNIOR, 2004).

Segundo Iwasso e Cafardo (2005), havia, em 1997, o total de 505 mil vagas para um universo de 392 mil alunos ingressantes. Em poucos anos este número mais do que triplicou. Em 2003 foram 1 milhão e 721 mil vagas e 995 mil alunos. Em 2005, o setor já contava com 
42\% de vagas ociosas em 1762 instituições de ensino particulares, sendo que 998 delas possuíam menos de dez anos de existência e, dessas, 935 possuíam menos de 500 alunos.

Este crescimento acelerado gerou impactos no faturamento do setor, segundo estudo da Consultoria Hoper (2009). O crescimento do número de instituições de ensino privadas foi maior que o crescimento do faturamento do setor, promovendo a diluição da receita por instituição, que foi cerca de $\mathrm{R} \$ 10,0$ milhões em 2008. Constatou-se, também, que o setor era concentrado, com $5 \%$ das instituições de ensino concentrando $54,6 \%$ do faturamento do setor no ano de 2008.

Por outro lado, Iwasso e Cafardo (2007) apresentam que, nos anos de 2006 e 2007, o crescimento do número de instituições de ensino superior privadas no Brasil foi de apenas 0,14\%, demonstrando o início de uma desaceleração, sobretudo se comparado com os períodos anteriores, em que houve um crescimento médio de $13 \%$ entre os anos de 1997 e 2005. Além disso, o fator valor das mensalidades passou a chamar a atenção, tendo em vista que ele tem apresentado contínuo decréscimo ao longo dos anos. Todo este cenário remete a um eminente acirramento da competição no setor. Esta premissa também se confirma quando se analisa a taxa de matrículas conforme o Instituto Nacional de Estudos e Pesquisas Educacionais Anísio Teixeira (INEP), demonstrando um crescimento mais retraído no respectivo período, sobretudo entre os anos de 2008 e 2009, quando houve decréscimo.

Quadro 1 - Evolução do Número de Matrículas de Graduação - Educação Superior Privada Presencial

\begin{tabular}{|c|c|}
\hline Ano & $\begin{array}{c}\text { Número de matrículas de graduação presencial em } \\
\text { Instituições Privadas de Ensino Superior }\end{array}$ \\
\hline 2002 & 2.428 .258 \\
\hline 2003 & 2.750 .652 \\
\hline 2004 & 2.985 .405 \\
\hline 2005 & 3.260 .967 \\
\hline 2006 & 3.467 .342 \\
\hline 2007 & 3.639 .413 \\
\hline
\end{tabular}




\begin{tabular}{|c|c|}
\hline 2008 & 3.806 .091 \\
\hline 2009 & 3.764 .728 \\
\hline 2010 & 3.987 .424 \\
\hline 2011 & 4.151 .371 \\
\hline
\end{tabular}

Fonte: Adaptado pelo autor com dados do Censo da Educação Superior 2011 (Instituto Nacional de Estudos e Pesquisas Educacionais Anísio Teixeira, 2012, p. 94).

A partir de então, o presente trabalho propõe-se a realizar um estudo da avaliação das capacidades e recursos estratégicos de sete instituições privadas de Ensino Superior, utilizando como referência o modelo de Barney e Hesterly (2007), no sentido de se fornecer dados e informações não apenas para as instituições pesquisadas, como a todo o setor de educação superior privada no Brasil. Este modelo foi adotado por entender as necessidades de se compreender as consequências competitivas e as implicações sobre o desempenho resultantes da combinação dos quatro critérios do Valor, Raridade, Imitabilidade e Organização (VRIO). Além disso, este caminho permite aos gestores, investidores e estudiosos da área conhecer (e explorar) recursos que geram vantagem competitiva sustentável.

\section{REFERENCIAL TEÓRICO}

Para compreender melhor a necessidade de uma análise estratégica de determinada empresa ou setor, faz-se necessário entender os quatro paradigmas tradicionais no campo da estratégia empresarial, conforme assertiva de Teece, Pisano e Shuen (1997). A presente seção busca apresentar, inicialmente, uma análise geral e posteriormente uma análise aprofundada dos respectivos paradigmas, que servirão de base para a análise dos dados coletados.

De forma geral, o primeiro paradigma considera que a estratégia competitiva envolve a tomada de ações ofensivas e defensivas, com o objetivo de criar uma posição defensável contra forças competitivas. Esse paradigma é nomeado como abordagem das forças competitivas, sendo muito associado a Porter (1980). Tem origem em estudos sobre o desempenho e a conduta estrutural e através dos trabalhos seminais de Mason $(1939,1949)$ sobre preço, políticas de produção e economias de escala, e de Bain $(1956,1959)$ sobre 
barreiras à competição e do modelo condicionante de estrutura industrial e performance de Scherer (1980).

O segundo paradigma tem como base a literatura da nova organização industrial, concentra-se nas barreiras de entrada e nas interações estratégicas. Possui como principal expoente Shapiro (1989), além dos estudiosos da economia dos jogos. Considera que o produto industrial é função da efetividade, com a qual firmas mantêm seus rivais desequilibrados, através de estratégias de investimentos, estratégias de preços, sinalizações e controle da informação.

A terceira abordagem, comumente chamada da perspectiva baseada em recursos, dá ênfase às capacidades específicas da firma e na existência de mecanismos isolados que são considerados fundamentais para a performance da firma. Tem como fontes iniciais os trabalhos de Penrose (1959), Rumelt (1984), Teece $(1984,1988)$ e Wernefelt e Montgomery (1988).

Teece, Pisano e Shuen (1997) sugerem o surgimento de uma quarta abordagem, chamada de paradigma das competências dinâmicas, oriundo da abordagem baseada em recursos, mas distinta desta. O termo competências dinâmicas é utilizado, tendo em vista a importância do desenvolvimento de novas competências, bem como a exploração das antigas, o que conduz a diferentes normativas para o estudo de estratégia. A seguir, o presente trabalho promove uma discussão sobre os quatro paradigmas supracitados.

\subsection{O PARADIGMA DAS FORÇAS COMPETITIVAS}

Porter (1980) considera a existência de cinco forças que influenciam a concorrência da indústria (figura 1): ameaça de novos entrantes, rivalidade entre concorrentes existentes, ameaça de produtos ou serviços substitutos, poder de barganha dos fornecedores e poder de barganha dos compradores. O conjunto destas cinco forças determina o potencial de lucro final na indústria, medido em termos de retorno em longo prazo sobre o capital investido. A meta da estratégia competitiva é encontrar uma posição favorável dentro da indústria, de tal forma que possa controlar essas forças e influenciá-las a seu favor.

Figura 1 - Forças que dirigem a concorrência da Indústria 


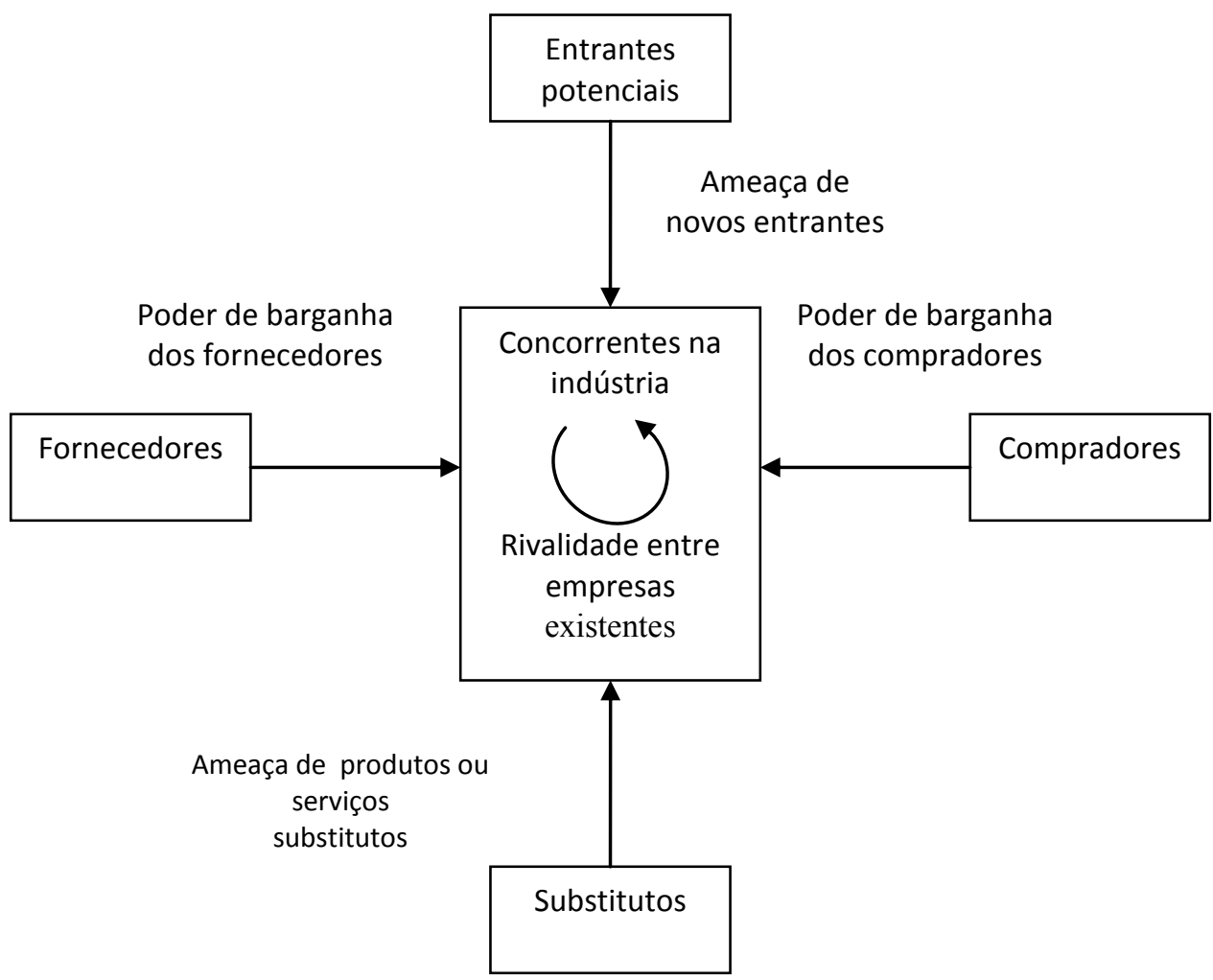

Fonte: Porter (1986, p. 23).

Uma vez diagnosticada a influência das cinco forças sobre a indústria, o modelo de Porter (1986) sugere o posicionamento da empresa com relação às causas básicas de cada força competitiva. A estratégia competitiva possui, desta forma, o papel de criar uma posição defensável contra as cinco forças competitivas.

Após o entendimento do comportamento das cinco forças no nível da indústria, o modelo de Porter (1980) volta-se para a análise da concorrência, que tem como objetivo entender como cada competidor responde aos movimentos estratégicos dos concorrentes, bem como toma iniciativa de gerar seus próprios movimentos. Neste sentido, são identificados quatro componentes para a análise: objetivos futuros, estratégia corrente, suposições e competências. Cabe ressaltar a pouca importância dada à questão das competências, que se restringem à análise das forças e fraquezas dos concorrentes:

Desde que a noção das forças e fraquezas dos concorrentes é relativamente clara, eu não vou me estender nessa discussão. Em uma visão mais ampla, forças e fraquezas podem ser acessadas pela análise da posição dos competidores com relação às cinco forças competitivas (PORTER, 1980, p. 63). 
Como observado por Teece, Pisano e Shuen (1997), o modelo das cinco forças de Porter (1980) não possui um aparato conceitual ou um esquema analítico por detrás de suas taxonomias. Para executivos do mundo empresarial, isso não gera problemas aparentes; porém, para pesquisadores que buscam fundamentos nas teorias gerenciais, o modelo apresenta limitações. As premissas apresentadas no modelo também podem ser questionadas, ou seja, os limites da indústria são significantes, a estrutura da indústria determina as regras competitivas, as competências são mais bem mapeadas no nível funcional e o caixa é, talvez, a única restrição de reposição da empresa. Por outro lado, o modelo de Porter (1980) é amplo e inclusivo, o que torna qualquer fator concebível pelo menos mencionado, o que, segundo Teece, Pisano e Shuen (1990), passa a ser outra limitação do modelo. Isso porque passa a impressão falaciosa de que pode explicar todos os fenômenos existentes na competitividade da indústria:

[...] No entanto, o framework proposto por Porter é amplo e inclusivo, o que significa que praticamente todos os fatores concebíveis são pelo menos mencionados. Na verdade, a principal queixa que nós temos não é que Porter deixou algo de fora, mas que ele deixou muito dentro, no propósito de delinear um framework sobre a qual outros podem construir. Adicionalmente, este amplo framework não é facilmente refutável. (TEECE; PISANO; SHUEN, 1990, p. 5, tradução nossa).

\subsection{O PARADIGMA DAS BARREIRAS DE ENTRADA E DAS INTERAÇÕES ESTRATÉGICAS}

Uma nova corrente sobre estratégia é oriunda do artigo de Shapiro (1989), The Theory of Bussiness Strategy ${ }^{1} m$ intitulada como a nova organização industrial. Baseia-se no estudo das interações estratégicas entre empresas e nas possibilidades de criação de barreiras de entradas que, nesse caso, podem estar associadas à competição entre firmas existentes. Toma como base o estudo de Schelling (1960), Strategy of Comflict ${ }^{2}$, que define um movimento estratégico como sendo uma ameaça, uma promessa ou um compromisso, cujo objetivo é influenciar o comportamento dos outros. Esta influência, traduzida no âmbito dos negócios, por ser percebida como eficaz na medida em que gera elevados retornos para o proponente e influencia nas decisões dos entrantes potenciais. A influência nas firmas ocorre no nível dos custos e da demanda. Para serem efetivos, esses movimentos estratégicos exigem compromissos irreversíveis. A análise dos movimentos estratégicos

\footnotetext{
${ }^{1}$ Em Português: A teoria da Estratégia de Negócios.

${ }^{2}$ Em Português: Estratégia do conflito.
} 
pode ser interpretada como uma ação em uma competição dinâmica, em um ambiente altamente restrito.

O principal instrumento para análise dessas questões é a Teoria dos Jogos, que explica como indivíduos e firmas comportam-se em situações de cooperação e de conflito. As escolhas da firma dependem das escolhas de outras firmas e, simultaneamente, também influencia as escolhas dessas outras firmas. As firmas são vistas, desta forma, como agentes flexíveis e sofisticados, elaborando estratégias de negócios que levam em consideração as respostas dos rivais, em um processo de interações estratégicas dinâmicas. Elas são consideradas como maximizadoras de lucros, e com um comportamento de nãocooperação. O comportamento é considerado como não estratégico se alguma das ações correlatas pode ser realizada com custos menores. Esse paradigma esforça-se para distinguir as decisões estratégicas de longo prazo das decisões táticas de curto prazo. Shapiro (1989) sumariza exemplos de fatores que influenciam nessas decisões estratégicas, tais como o investimento em capital físico, os investimentos em recursos intangíveis, o controle estratégico da informação e a rede de competição.

A principal contribuição desse paradigma está na sua estrutura implícita utilizada para discussão de temas ligados à gestão. Como limitações, Teece, Pisano e Shuen (1997) consideram que o mesmo vê a vantagem competitiva surgindo da desorientação e das práticas restritivas, havendo uma tendência de considerar que as equações teóricas são guias normativos para a formulação de políticas, o que geralmente não ocorre na maioria dos casos. Ao ver a dinâmica das interações estratégicas ao longo do tempo, dispensa pouca atenção às competências e habilidades únicas, bem como ao processo de desenvolvimento e de acumulação das mesmas. Neste sentido, Dierickx e Cool (1989) argumentam que a teoria dos jogos e a abordagem das barreiras de entrada consideram que as firmas possuem competências homogêneas, e o sucesso estratégico é resultado de sofisticados jogos e interações, e não fruto da construção de competências e de recursos únicos, o que leva os praticantes a se concentrarem mais no posicionamento de mercado que no desenvolvimento dessas competências que, por sua vez, gerariam uma posição superior de mercado. Teece, Pisano e Shuen (1997) também argumentam que essa abordagem conduz os praticantes a uma visão de que a competição é baseada no curto prazo e apenas nos recursos já existentes, o que apenas em limitadas situações pode gerar vantagem 
competitiva sustentável, tornando esses autores céticos quanto ao valor acrescentado pela teoria dos jogos para a formulação estratégica de empresas. Geroski (1988) também estabelece críticas à teoria dos jogos ao afirmar que a mesma não vai além de apresentar uma formalização de argumentos e ideias que são amplamente conhecidos e aceitos. Ela também é baseada mais em pressupostos do que em evidência empírica.

\subsection{O PARADIGMA DA VISÃO BASEADA EM RECURSOS}

O terceiro paradigma da estratégia da competição tem origem nos estudos de Penrose (1962) sobre o crescimento da firma, onde a mesma é vista como um conjunto de recursos devidamente organizados. O modo como a empresa organiza esses recursos seria, segundo Penrose (1962), o responsável pelo seu crescimento. Learned et al. (1969) consideram que a capacidade de uma organização é sua habilidade, demonstrada e potencial de realização, independente das circunstâncias existentes de competição, e que seu sucesso depende de sua capacidade de desenvolver uma competência que seja realmente distinta. Tomando como base essas proposições, Wernefelt (1984) propõe o paradigma da visão baseada em recursos $(\mathrm{RBV})^{3}$, onde estes podem ser definidos como ativos tangíveis e intangíveis controlados pela empresa, e que podem ser utilizados para a geração de vantagens competitivas. Ainda dentro das proposições, Wernefelt (1984) apresenta o conceito de capacidades, que são vistas como um conjunto de recursos de uma empresa. Elas são também vistas como ativos tangíveis e intangíveis e que permitem à empresa utilizar por completo outros recursos que a mesma controla. Elas, por si só, não permitem a criação e a implementação de estratégias. Porém, permitem a utilização de outros recursos para tal.

Os recursos e capacidades podem, ainda, ser classificados em quatro categorias: recursos financeiros, recursos físicos, recursos individuais e recursos organizacionais. Os primeiros compreendem todo o dinheiro, de qualquer fonte, utilizado pela empresa. Os segundos incluem toda a tecnologia física utilizada pela empresa, tais como plantas, equipamentos, acesso a matérias-primas e localização geográfica. Os recursos humanos englobam treinamento, experiência, julgamento, inteligência, relacionamentos e a visão individual dos funcionários. Finalmente, os recursos organizacionais são relativos a grupos

\footnotetext{
${ }^{3}$ Em inglês: Resource Based View.
} 
de pessoas, incluindo a estrutura formal de reporte da empresa, os seus sistemas formais e informais de planejamento, controle e coordenação, cultura, reputação, relações informais entre funcionários e agentes externos à empresa.

Como observado por Barney e Hesterly (2007), a RBV baseia-se em duas suposições fundamentais sobre os recursos e capacidades. A primeira é a suposição da heterogeneidade de recursos da empresa; ou seja, é a suposição de que diferentes empresas podem possuir diferentes conjuntos de recursos e capacidades, mesmo que competindo em um mesmo setor. A segunda suposição é a da imobilidade de recursos, a qual considera que algumas das diferenças de recursos e capacidades encontradas entre empresas podem ser duradouras, em função do custo existente para o desenvolvimento ou para a aquisição dos mesmos. Essas duas suposições, juntas, permitem explicar por que determinadas empresas superam outras, ainda que competindo em um mesmo setor. Firmas que possuem esses ativos tangíveis e intangíveis podem obter vantagem competitiva sustentável. Neste sentido, essa abordagem considera que o resultado financeiro da empresa é mais decorrente de suas capacidades e recursos desenvolvidos ao longo do tempo do que do estabelecimento de um posicionamento específico de mercado.

Tomando como base os fundamentos estabelecidos por Wernefelt (1984), Barney (1991,1995) propõe o modelo VRIO, utilizado para análise da ambiência interna das empresas, ou seja, de suas forças e fraquezas. O VRIO apresenta quatro questões a serem levantadas sobre os recursos e sobre as capacidades para determinar o seu potencial competitivo: as questões do Valor, da Raridade, da Imitabilidade e da Organização. A primeira indaga se os recursos e capacidades permitem que uma empresa explore uma oportunidade externa ou neutralize uma ameaça externa. Em afirmativo, esses recursos serão considerados valiosos, sendo vistos como forças da empresa. Uma maneira de identificar o impacto dos recursos e das capacidades é avaliar as receitas e os custos. Caso eles sejam forças, permitem o aumento das receitas líquidas ou o decréscimo dos custos líquidos, ou ambos.

A segunda questão, a da raridade, leva em consideração a existência de outras empresas concorrentes detentoras de recursos e capacidades valiosos. Caso estes sejam controlados por uma quantidade de concorrentes, dificilmente será fonte de vantagem 
competitiva. A terceira questão diz respeito à imitabilidade, em outras palavras, leva em consideração a dificuldade que empresas concorrentes possuem para imitar determinados recursos e capacidades. Dito de outra maneira, as empresas que não os detêm enfrentam desvantagem de custo para obtê-lo ou desenvolvê-lo.

Finalmente, a questão da organização argumenta se a empresa está organizada para explorar ao máximo o potencial competitivo de seus recursos e capacidades. Para a questão da organização, componentes como a estrutura formal de reporte, seus sistemas formais e informais de controle gerencial e suas políticas de remuneração são relevantes. Estes componentes são considerados como recursos e capacidades complementares, uma vez que, isoladamente, possuem capacidade limitada de geração de vantagem competitiva. Entretanto, uma vez combinados com outros recursos e capacidades, podem gerar vantagem competitiva (AMIT; SCHOEMAKER, 1993).

O quadro 2 resume as consequências competitivas e as implicações sobre o desempenho resultantes da combinação dos quatro critérios do VRIO.

Quadro 2 - Resultados das combinações dos critérios de vantagem competitiva

\begin{tabular}{|l|l|l|l|l|l|}
\hline $\begin{array}{c}\text { O recurso ou } \\
\text { capacidade é } \\
\text { valioso? }\end{array}$ & $\begin{array}{c}\text { O recurso ou } \\
\text { capacidade é } \\
\text { raro? }\end{array}$ & $\begin{array}{c}\text { O recurso ou } \\
\text { capacidade é } \\
\text { difícil de } \\
\text { imitar? }\end{array}$ & $\begin{array}{c}\text { O recurso ou } \\
\text { capacidade é } \\
\text { explorado pela } \\
\text { organização? }\end{array}$ & $\begin{array}{c}\text { Consequências } \\
\text { competitivas }\end{array}$ & $\begin{array}{c}\text { Implicações } \\
\text { sobre o } \\
\text { desempenho }\end{array}$ \\
\hline Não & Não & Não & Não & $\begin{array}{l}\text { Desvantagem } \\
\text { competitiva }\end{array}$ & $\begin{array}{l}\text { Retornos abaixo } \\
\text { da média }\end{array}$ \\
\hline $\operatorname{Sim}$ & Não & Não & Sim/Não & $\begin{array}{l}\text { Paridade } \\
\text { competitiva }\end{array}$ & $\begin{array}{l}\text { Retornos } \\
\text { equivalentes à } \\
\text { média }\end{array}$ \\
\hline $\operatorname{Sim}$ & Sim & Não & Sim/Não & $\begin{array}{l}\text { Vantagem } \\
\text { competitiva } \\
\text { temporária }\end{array}$ & $\begin{array}{l}\text { Retornos } \\
\text { equivalentes e } \\
\text { superiores à } \\
\text { média }\end{array}$ \\
\hline $\operatorname{Sim}$ & Sim & Sim & Sim & $\begin{array}{l}\text { Vantagem } \\
\text { competitiva } \\
\text { sustentável }\end{array}$ & $\begin{array}{l}\text { Retornos acima } \\
\text { da média }\end{array}$ \\
\hline
\end{tabular}

Fonte: Adaptado de Barney e Hesterly (2007).

Recursos e capacidades que não são valiosos nem raros, mas que são imitáveis e que possuem substitutos estratégicos, não devem ser enfatizados na formulação estratégica por 
gerarem desvantagem competitiva. Recursos e capacidades que geram paridade competitiva ou vantagem competitiva temporária ou sustentável devem ser enfatizados, uma vez que podem gerar retornos equivalentes à média do setor ou superiores.

De acordo com o quadro 3, recursos que não são valiosos não permitem que a empresa escolha estratégias que explorem oportunidades e que neutralizem as ameaças. Esses recursos podem aumentar os custos da empresa e diminuir suas receitas, colocando-a em desvantagem competitiva. Um recurso ou capacidade valioso, mas não raro, pode gerar paridade competitiva. Deixar de explorá-lo pode colocar a empresa em desvantagem competitiva. Desta forma, recursos valiosos, mas não raros, podem ser vistos como forças organizacionais. Recursos ou capacidades valiosos e raros, cuja imitação não é custosa, podem gerar vantagem competitiva temporária. Consequentemente, pode ser visto como uma força organizacional e como uma competência diferencial. A exploração de um recurso ou capacidade valioso, raro e custoso de imitar gera vantagem competitiva sustentável.

Quadro 3 - A relação entre o modelo VRIO e as forças e fraquezas organizacionais

\begin{tabular}{|c|c|c|c|c|}
\hline \multicolumn{5}{|c|}{ Um recurso ou capacidade é: } \\
\hline Valioso? & Raro? & Custoso de Imitar? & Explorado pela & Força ou Fraqueza? \\
\hline Não & - & - & Não & Fraqueza \\
\hline Sim & Não & - & & Força \\
\hline Sim & Sim & Não & & $\begin{array}{l}\text { Força } \\
\text { competência } \\
\text { distintiva }\end{array}$ \\
\hline Sim & Sim & Sim & Sim & $\begin{array}{l}\text { Força } \\
\text { competência } \\
\text { distintiva } \\
\text { sustentável }\end{array}$ \\
\hline
\end{tabular}

Fonte: Barney e Hesterly (2007). 
Empresas concorrentes possuem desvantagens de custo significativas para imitar esses recursos e capacidades, o que as coloca em posição de desvantagem competitiva. Esses tipos de recursos e capacidades são forças organizacionais e competências diferenciais sustentáveis.

A questão da organização reflete a propensão da empresa de utilizar os recursos e capacidades. Uma empresa que não se organize para tirar proveito de recursos e capacidades valiosos, raros e custosos de imitar pode perder parte de sua vantagem competitiva potencial ou ganhar apenas paridade competitiva ou desvantagem competitiva. Uma capacidade que satisfaça os quatro critérios de vantagem competitiva, presentes no VRIO, pode ser chamada de competência essencial. Caso contrário, é apenas um conjunto não estratégico de recursos.

Como crítica à RBV, Porter (1986) afirma que a concentração da estratégia de uma empresa apenas nos recursos e competências a leva a olhar apenas para si, sem levar em consideração as tendências do setor e a posição competitiva da empresa:

Concentrando-se somente nos recursos/competências e ignorando a posição competitiva, corre-se o risco de olhar apenas para si. Recursos ou competências são de grande valor para uma determinada posição ou forma de competição, não em si. Embora possa ser útil, a perspectiva dos recursos/competências não diminui a necessidade crucial de um determinado negócio entender a estrutura do setor e a posição competitiva. Mais uma vez, a necessidade de conectar os fins (a posição da empresa no mercado) e os meios competitivos (que elementos possibilitam a obtenção dessa posição) não é apenas crucial, é essencial (PORTER, 1986, p.11).

Finalmente, pode-se considerar, que a RBV foca-se não somente na identificação de recursos específicos que possam gerar rendimentos para a firma. Ela também estimula o desenvolvimento de novos recursos e capacitações. Se o controle sobre os recursos escassos é a fonte de lucros, a aquisição e o desenvolvimento de habilidades e competências configuram um tema fundamental para a estratégia. Sob esses princípios de aquisição de habilidades, de aprendizado e acumulação de competências, Teece, Pisano e Shuen (1990, 1997) propõe o quarto paradigma, o das Competências Dinâmicas, discutido a seguir.

\subsection{O PARADIGMA DAS COMPETÊNCIAS DINÂMICAS}

Revista Eletrônica de Estratégia \& Negócios, Florianópolis, v.7, n.3, set./dez. 2014. 
O paradigma das competências dinâmicas tem como fundamento a perspectiva baseada em recursos, utilizando-se a noção de que o crescimento rentável das firmas é oriundo de um processo de exploração de competências existentes e do desenvolvimento de novas competências, sugerido por Penrose (1959), Teece (1980, 1982), e Wernefelt (1984). Somando a esses trabalhos, Dierickx e Cool (1989) argumentam que a formulação estratégica pode ser considerada como um desafio de se fazer escolhas em investimentos estratégicos (gastos de propaganda, pesquisa e desenvolvimento, entre outros) com a visão de acúmulo de recursos e de habilidades necessárias (marca, expertise tecnológica, entre outros).

Hayes, Wheelwright e Clarck (1988), em complemento ao trabalho de Dierickx e Cool (1989), consideram que a principal proposta para a gestão estratégica é o foco no desenvolvimento de competências organizacionais específicas e relacionamentos que são difíceis de serem copiados no longo prazo. Tomando como base essas proposições e buscando estabelecer fundamentação para análise do processo de desenvolvimento e acúmulo de competências, a teoria das competências dinâmicas busca referência em Schumpeter (1942), Penrose (1959), Williamson (1975, 1985), Nelson e Winter (1982) e Teece (1988).

Visto dessa forma, Teece, Pisano e Shuen (1990) consideram que a perspectiva da firma, sugerida pelo paradigma das Competências Dinâmicas, é mais rica que a perspectiva apresentada pelo paradigma da visão baseada em recursos que, por sua vez, considera a empresa como um feixe de recursos. Em outras palavras, não é somente esse conjunto de recursos que importa, mas os mecanismos com os quais as firmas acumulam e disseminam novas habilidades e capacidades, bem como as forças que limitam a taxa e a direção desse processo.

Neste sentido, é importante estabelecer três discussões: (i) como a firma aprende novas habilidades, (ii) quais são as forças que limitam e focam o processo de aprendizagem, e (iii) a seleção do ambiente.

A primeira discussão considera que o aprendizado é um processo no qual a repetição e a experimentação permitem melhor e mais rápido desempenho, e geram novas 
oportunidades de produção. O aprendizado empresarial depende mais de habilidades organizacionais do que habilidades individuais, o que o torna um fenômeno social e coletivo dependente de rotinas. Essas rotinas são consideradas por Nelson e Winter (1982) como o molde de interações que representam soluções de sucesso para problemas específicos. Em função da complexidade desse processo, o conhecimento impregnado nas rotinas não pode ser facilmente imitado, o que Ihe configura uma dimensão tácita. Em outras palavras, essas rotinas próprias da organização, juntamente com a habilidade gerencial para mobilizar a organização em função de um resultado, constituem a competência da firma, podendo distingui-la de seus competidores.

A segunda discussão, a das forças que restringem e direcionam o processo de aprendizado, engloba cinco dimensões: a dependência da trajetória, os ativos complementares, as oportunidades tecnológicas, as janelas e o tempo de ação estratégica e os custos de transação. A noção de dependência de trajetória considera que a história da organização é importante; ou seja, os investimentos do passado, bem como seu repertório de rotinas influenciam no seu comportamento futuro. Os ativos complementares estão relacionados com a trajetória. A priorização de determinadas atividades exige e permite que a firma desenvolva esses ativos que, além de necessários para as atividades prioritárias, também possuem outras utilizações no processo de desenvolvimento de produtos e na cadeia de valor.

As oportunidades tecnológicas da indústria influenciam as trajetórias de dependência. É sabido que a velocidade com que uma área particular da indústria pode processar suas atividades é influenciada pelas escolhas tecnológicas realizadas no passado. As janelas e o tempo para a ação estratégica representam o aproveitamento das janelas de oportunidades para a entrada em novos negócios, a obtenção de novas fatias de mercado ou a introdução de novos produtos. Finalmente, a quinta dimensão, a dos custos de transação, que podem desestimular a intenção por parte da firma ou de seus concorrentes de desenvolverem determinadas competências (TEECE; PISANO; SHUEN, 1990).

A terceira discussão, a da seleção ambiental, é importante na medida em que estimula a firma a desenvolver novas competências. Para Teece, Pisano e Shuen (1990), ela pode ser caracterizada como frouxa ou apertada. A seleção frouxa é permissiva, fazendo 
com que firmas menos eficientes possam sobreviver. A seleção apertada é normalmente caracterizada por uma elevada competição, fazendo com que as firmas menos eficientes sejam excluídas.

Quando uma competência tecnológica é fortemente dependente da trajetória, o impacto de uma mudança radical na tecnologia dominante será dependente da seleção ambiental. Em um a seleção frouxa, os agentes possuem maior fôlego para desenvolver as novas competências. Novos entrantes podem, em contraste, aniquilar com os agentes em uma competição apertada. Em determinados ambientes, certas competências são fundamentais, como aquelas exigidas para atuação em setores específicos de engenharia, produção ou marketing, o que faz com que a seleção ambiental atue com uma força homogeneizadora.

A discussão sobre competências dinâmicas realizada gera várias implicações para a estratégia. Para Teece, Pisano e Shuen (1997), a vantagem competitiva é função de um conjunto de competências centrais e seus relacionamentos com clientes e fornecedores. A existência dessas competências explica, por exemplo, porque plantas e equipamentos similares produzem mais e melhor em diferentes companhias.

As normativas para o campo de estratégia, segundo Teece, Pisano e Shuen (1997), podem ser avaliadas em seis dimensões: quanto ao foco analítico, quanto à mudança estratégia, quanto às estratégias de entrada, quanto ao momento de entrada, quanto à diversificação e quanto ao foco e à especialização. Com relação ao foco analítico, pode-se observar que as competências dinâmicas e a RBV propõem uma análise estratégica situacional. Não existe um algoritmo que sistematize o melhor caminho a ser seguido. Prescrições, no máximo, podem estabelecer direções gerais.

Quanto à mudança estratégica, as forças competitivas e as barreiras de entrada tendem a ver a escolha estratégica como algo a ser feito com certa facilidade. Isso ocorre dada a pouca importância que destinam às habilidades e à trajetória de acumulação de competências. Por outro lado, a abordagem dos recursos e das competências vê a mudança estratégica com algo custoso e difícil de ser realizado. As competências não podem ser facilmente adquiridas. Elas devem ser construídas em um processo de longo prazo. 
Com relação às estratégias de entrada, a abordagem dos recursos e das capacidades considera que as decisões de entrada devem ser feitas tomando-se como base as competências que os novos entrantes possuem e as competências exigidas pela indústria. Enquanto as cinco forças e as barreiras de entrada sugerem uma busca quase que irrestrita por novos mercados, a abordagem dos recursos e capacidades considera que as novas oportunidades estão próximas dos negócios já dominados pela empresa. Quanto ao momento de entrada, enquanto a abordagem das barreiras de entrada e a das forças competitivas dizem pouco sobre os possíveis entrantes, as abordagens dos recursos e das competências dinâmicas identificam quais são esses novos entrantes, bem como o seu momento de entrada. Quanto maior o número de recursos e de competências que uma firma possui, maior a sua possibilidade de entrar em novos mercados. Adicionalmente, a interação entre as competências específicas de uma firma e as de seus rivais possui grande influência no momento de entrada em novos mercados.

Quanto à diversificação, apenas aquelas provenientes da extensão das capacidades e recursos são vistas como meritocráticas, pois são justificáveis quando mercados tradicionais da firma entram em declínio. Nas barreiras de entrada, isso provavelmente será mais permissivo, uma vez que aquisições que aumentam os custos dos rivais, ou permitem as firmas desenvolverem arranjos específicos, são prováveis de serem mais eficazes. Quanto ao foco e à especialização, a RBV e as Competências Dinâmicas consideram que o foco deve ser visto em termos de capacidades e não de produtos. Essa abordagem enfatiza muito mais a identificação dos recursos e capacidades necessárias para participar do jogo, enquanto as abordagens das forças e das barreiras está voltada para a maneira como o mesmo é jogado.

\section{METODOLOGIA}

Malhotra (2006) apresenta que, em uma pesquisa exploratória, objetiva-se fazer a busca em um problema ou em uma situação para fornecer critérios para sua maior compreensão.

Aplicando a classificação acima, entende-se que a pesquisa possui caráter exploratório, realizado inicialmente através da revisão teórica sobre o tema, levantamento de relatórios e publicações sobre o setor de educação. A partir de então, foi realizado um 
estudo da avaliação das capacidades e recursos estratégicos de sete instituições privadas de ensino superior, utilizando-se de entrevistas com seus executivos, com o intuito de estabelecer uma análise complementar.

O presente trabalho adotou a estratégia de multicasos. O tipo de caso adotado foi o projeto holístico de casos múltiplos, conforme assertiva de Yin (2005), uma vez que o estudo adota, como unidades de análise isoladas, sete instituições privadas de ensino superior. Os dados foram coletados através de documentos disponíveis internamente às empresas estudadas, bem como em relatórios e estatísticas específicas sobre o setor, em portais, em jornais e revistas. Também foi adotada a coleta de dados por meio de entrevistas semiestruturadas com doze executivos das instituições analisadas entre os anos de 2009 e 2010, conforme quadro 4:

Quadro 4 - Gestores entrevistados

\begin{tabular}{|c|c|c|}
\hline Instituição & Cargo & Nomeação \\
\hline \multirow{4}{*}{ Grupo Anima de Educação } & Presidente & Entrevistado 1 \\
\hline & Vice-Presidente de Operações & Entrevistado 2 \\
\hline & Vice-Presidente de Expansão & Entrevistado 3 \\
\hline & Diretora acadêmica & Entrevistado 4 \\
\hline \multirow{2}{*}{ Centro Universitário UNA } & Reitor & Entrevistado 5 \\
\hline & Vice-Reitor & Entrevistado 6 \\
\hline Centro Universitário Unimonte & Vice-Reitor & Entrevistado 7 \\
\hline Centro Universitário UNIBH & Vice-Reitor & Entrevistado 8 \\
\hline Kroton & Diretor Geral & Entrevistado 9 \\
\hline Anhanguera & Diretor Geral & Entrevistado 10 \\
\hline Estácio de Sá & Coordenador & Entrevistado 11 \\
\hline PUCMINAS & Pró-reitor & Entrevistado 12 \\
\hline
\end{tabular}


Fonte: Elaborado pelo autor.

A amostra selecionada para o estudo é representada pelas instituições de ensino: Centro Universitário UNA, Centro Universitário Unimonte, Centro Universitário UNIBH, Kroton (que se funde ao Grupo luni Educacional em 2010), Anhanguera, Estácio de Sá e PUCMINAS. Tais instituições foram escolhidas por refletirem a realidade do setor em questão, constituído por Faculdades, Centros Universitários, Universidades, por Instituições Filantrópicas e Instituições com Fins Lucrativos, por Instituições com capital aberto ou não e por Instituições com operação individualizada ou em rede.

Para a análise de dados foi adotada a Técnica de Análise de Conteúdo Categoria, segundo preceitos de Bardin (2009). Esta análise foi realizada nas entrevistas efetuadas e nos materiais coletados, utilizando o Software NVIVO9 4 para o devido tratamento. Após os dados serem categorizados, eles foram analisados seguindo modelo de Barney e Hesterly (2007), descritos nos quadros 2 e 3 do respectivo trabalho.

Como limitação, foi acordado com os gestores que as entrevistas, no que se refere à estratégia das organizações, não seriam divulgadas.

\section{RESULTADOS DA PESQUISA}

A avaliação das capacidades e recursos que influenciam a competitividade das empresas foi feita tendo como base o quadro 2 e 3 , que representam o modelo VRIO e os impactos sobre a vantagem competitiva das empresas, adaptado de Barney e Hesterly (2007). Os dados utilizados para as inferências foram coletados das pesquisas documental e entrevista com os gestores. Vale a pena observar que há certa distinção entre Universidades, Centros Universitários e Faculdades, e isto também foi considerado para a análise dos dados.

\subsection{CENTRO UNIVERSITÁRIO UNA}

O Centro Universitário UNA é uma instituição com mais de meio século de existência (fundada em 1961), situada na cidade de Belo Horizonte. Possui cerca de vinte mil alunos distribuídos em diferentes áreas do conhecimento. Tem demonstrado destaque em seu mercado pelo rápido crescimento a partir de 2003, ano em que foi adquirida pelo atual

\footnotetext{
${ }^{4}$ Disponível em: <www.qsrinternational.com/products_nvivo.aspx>.
} 
grupo controlador ${ }^{5}$, deixando de ser uma instituição com caráter familiar e desenvolvendo, a partir de então, uma gestão profissionalizada.

a) Desvantagem Competitiva:

- deficiência em processos;

- alguns indicadores ruins de acordo com a avaliação do MEC.

b) Paridade Competitiva:

- RH com pouca habilidade acadêmica;

- infraestrutura;

- Campi verticais.

c) Vantagem Competitiva Temporária:

- vários campi com boa localização em Belo Horizonte;

- liderança no ensino tecnológico;

- habilidade de explorar oportunidades de mercado não exploradas.

d) Vantagem Competitiva Sustentável:

- força da marca;

- agilidade e inteligência de negócios;

- cultura de inovação;

- recursos humanos;

- gestão executiva.

\subsection{CENTRO UNIVERSITÁRIO UNIBH}

\footnotetext{
${ }^{5}$ Grupo Ânima Educação,
}

Revista Eletrônica de Estratégia \& Negócios, Florianópolis, v.7, n.3, set./dez. 2014. 
O Centro Universitário UNIBH foi a segunda instituição analisada. Localizado em Belo Horizonte, possui mais de quatro décadas, fundado em 1964. Oferta mais de quarenta cursos de graduação e possui cerca de quinze mil alunos. Após uma forte crise financeira, foi adquirido pelo mesmo grupo controlador do Centro Universitário UNA em 2009. Desde então vem passando por um processo de reestruturação, que já apresenta sinais de reversão em seu desempenho financeiro.

a) Desvantagem Competitiva:

- processos, cultura e estrutura obsoleta;

- falta de capacidade de investimento;

- complexidade das relações políticas;

- gestão ruim.

b) Paridade Competitiva:

- recursos humanos docentes.

c) Vantagem Competitiva Temporária:

- boa qualidade acadêmica;

- relação afetiva dos funcionários e alunos com a instituição.

d) Vantagem Competitiva Sustentável:

- marca, qualidade, tradição, social e humana;

- penetração social e política;

- estrutura física.

\subsection{CENTRO UNIVERSITÁRIO UNIMONTE}

O Centro Universitário Unimonte é uma tradicional instituição de ensino fundada em 1971, localizada na cidade de Santos. Possui cerca de sete mil alunos também distribuídos 
em diversas áreas do conhecimento. Foi adquirida pelo atual grupo controlador dos Centros Universitários UNA e UNI-BH em 2007, após passar por problemas financeiros. Desde então vem passando por um processo de profissionalização de sua gestão. Embora demonstre melhorias em seu desempenho, não tem conseguido apresentar os mesmos resultados financeiros que as outras instituições do grupo, o que demonstra que os ganhos de competitividade não têm sido significativos.

a) Desvantagem Competitiva:

- posicionamento errado associado à qualidade e não melhor custo-benefício;

- $\quad$ mercado de atuação pequeno;

- nível de endividamento muito elevado;

- $\quad$ marca com elevada rejeição;

- falta de profissionalização interna.

b) Paridade Competitiva:

- $\quad$ avaliação MEC com nota 3.

c) Vantagem Competitiva Temporária:

- boa imagem institucional dos cursos tecnológicos;

- $\quad$ proximidade com o mercado corporativo.

d) Vantagem Competitiva Sustentável:

Não foram apresentados recursos/capacidades com essa característica.

\subsection{KROTON}

A Kroton Educacional é detentora da marca Pitágoras, onde atua em cursos do Ensino Médio e Fundamental, bem como no Ensino Superior. Com mais de quarenta anos, atua no ensino superior desde 2001, estando presente em sete estados brasileiros. No ano de 2007 
fez a abertura de seu capital, passando a ter ações ofertadas na bolsa de valores. A partir desse período, vive um movimento de forte expansão sem, entretanto, apresentar geração de valor adequada para o acionista.

a) Desvantagem Competitiva:

- $\quad$ ausência de uma política de meritocracia e premiação de resultados;

- instabilidade nos processos em função das reestruturações;

- $\quad$ ausência de uma cultura ainda não institucionalizada após a fusão (qualidade, inovação, etc.) entre a Kroton e o luni.

b) Paridade Competitiva:

- infraestrutura;

- localização dos campi.

c) Vantagem Competitiva Temporária:

- $\quad$ atuação em diversas regiões e cidades do país.

d) Vantagem Competitiva Sustentável:

- marca;

- gestão profissionalizada;

- capital aberto na Bolsa de Valores.

\subsection{ANHANGUERA}

A Anhanguera Educacional organizou-se como companhia de capital aberto em 2003, a partir das instituições Associação Lemense de Educação e Cultura, entidade mantenedora do Centro Universitário Anhanguera (Leme e Pirassununga); Faculdade Comunitária de Campinas e Faculdades Integradas de Valinhos, Instituto Jundiaiense de Educação e Cultura, entidade mantenedora da Faculdade Politécnica de Jundiaí; e Instituto de Ensino Superior 
Anhanguera, entidade mantenedora da Faculdade Politécnica de Matão. Vivenciou diversas fases de crescimento: a primeira, de expansão dos seus cursos superiores e de sua base física, até 1998; a segunda, de otimização e qualificação dos seus currículos e projetos pedagógicos, até 2003; e a terceira, de reorganização estrutural, administrativa e financeira, sendo essa última com o ingresso de novos parceiros-sócios e investidores. No ano de 2007, abriu seu capital na bolsa de valores, passando também a viver um período de forte expansão, sem conseguir uma geração de valor positiva para o período avaliado.

a) Desvantagem Competitiva

Não foram apresentados pelo entrevistados recursos/capacidades com essa característica.

b) Paridade Competitiva

Não foram apresentados pelo entrevistados recursos/capacidades com essa característica.

c) Vantagem Competitiva Temporária

- tecnologia da informação.

d) Vantagem Competitiva Sustentável

- capital aberto na Bolsa de Valores;

- gestão de Governança Corporativa em modelo matricial;

- economia de escala.

\subsection{ESTÁCIO DE SÁ}

Fundada em 1970 como escola de Direito Estácio de Sá, conta com cerca de 200 mil alunos e uma atuação em dezesseis estados do país. Em 2007 fez sua abertura de capital na bolsa de valores e, em 2008, passou a contar com o grupo GP Investiments como acionista e gestor do negócio. Vem proporcionando, ao investidor, uma boa geração de valor no período analisado.

a) Desvantagem Competitiva: 
- $\quad$ resistência ao novo modelo de gestão;

- passivo trabalhista.

b) Paridade Competitiva:

- $\quad$ tecnologia em EaD;

- $\quad$ padronização de cursos;

- gestão.

c) Vantagem Competitiva Temporária:

- $\quad$ equipe de gestores;

- $\quad$ recursos financeiros disponíveis.

d) Vantagem Competitiva Sustentável:

- capacidade de captação de alunos;

- economia de escala.

\subsection{PONTIFÍCIA UNIVERSIDADE CATÓLICA DE MINAS GERAIS}

A Pontifícia Universidade Católica de Minas Gerais (PUCMINAS) possui cerca de 60 mil alunos, com atuação em Belo Horizonte, Betim, Contagem, Poços de Caldas, Arcos, Serro e Guanhães. Foi fundada em 1968, através de sua mantenedora a Sociedade Mineira de Cultura. Em 1958, torna-se Universidade através de um decreto assinado por Juscelino Kubitschek e pelo então ministro da educação e cultura, Clóvis Salgado. É a maior instituição privada de Ensino Superior de Minas Gerais.

a) Desvantagem Competitiva

- Folha de pagamento muito elevada;

- Campi deficitários. 
ESTRATÉGIA E COMPETITIVIDADE: UM ESTUDO MULTICASO DA EDUCAÇÃO SUPERIOR PRIVADA BRASILEIRA

Ricardo Viana Carvalho de Paiva - Danilo de Melo Costa - Francisco Vidal Barbosa - Mário Teixeira Reis Neto

b) Paridade Competitiva

- técnicas de gestão organizacional.

c) Vantagem Competitiva Temporária

- vários campi em diferentes regiões do estado.

d) Vantagem Competitiva Sustentável

- marca;

- qualidade de ensino;

- corpo docente.

Finalmente, apresenta-se um quadro comparativo resumido com os principais resultados observados nas IES:

Quadro 5 - Principais resultados observados nas IES

\begin{tabular}{|c|c|c|c|c|}
\hline & Desvantagem Competitiva & Paridade Competitiva & $\begin{array}{c}\text { Vantagem Competitiva } \\
\text { Temporária }\end{array}$ & $\begin{array}{c}\text { Vantagem Competitiva } \\
\text { Sustentável }\end{array}$ \\
\hline UNA & $\begin{array}{l}\text { - Processos internos; } \\
\text { - Alguns indicadores } \\
\text { segundo o MEC. }\end{array}$ & $\begin{array}{l}\text { - RH; } \\
\text { - Infraestrutura; } \\
\text { - Campi. }\end{array}$ & $\begin{array}{l}\text { - Localização; } \\
\text { - Ensino tecnológico; } \\
\text { - Explora oportunidades } \\
\text { inéditas. }\end{array}$ & $\begin{array}{l}\text { - Marca; } \\
\text { - Agilidade e } \\
\text { inteligência de } \\
\text { negócios; } \\
\text { - cultura de inovação. }\end{array}$ \\
\hline UNI-BH & $\begin{array}{l}\text { - Processos; } \\
\text { - Investimento; } \\
\text { - Relações políticas; } \\
\text { - Gestão. }\end{array}$ & - RH (docentes) & $\begin{array}{l}\text { - Qualidade acadêmica; } \\
\text { - Relação afetiva dos } \\
\text { funcionários e alunos } \\
\text { com a instituição. }\end{array}$ & $\begin{array}{l}\text { - Marca; } \\
\text {-Penetração social e } \\
\text { política; } \\
\text {-Estrutura física. }\end{array}$ \\
\hline Unimonte & $\begin{array}{l}\text {-Posicionamento errado; } \\
\text { - Mercado pequeno; } \\
\text { - Endividamento; } \\
\text { - Marca. }\end{array}$ & - Avaliação MEC & $\begin{array}{l}\text { - Cursos tecnológicos; } \\
\text { - Proximidade com o } \\
\text { mercado corporativo. }\end{array}$ & $\begin{array}{l}\text { - Não foram } \\
\text { apresentados } \\
\text { recursos/capacidades } \\
\text { com essa característica. }\end{array}$ \\
\hline Kroton & $\begin{array}{l}\text { - Ausência de meritocracia; } \\
\text { - Ausência de Premiação de } \\
\text { resultados; } \\
\text { - Processos internos; }\end{array}$ & $\begin{array}{l}\text { - Infraestrutura; } \\
\text { - Localização. }\end{array}$ & $\begin{array}{l}\text { - Atuação em diversas } \\
\text { regiões. }\end{array}$ & $\begin{array}{l}\text { - Marca; } \\
\text { - Gestão; } \\
\text { - Capital aberto. }\end{array}$ \\
\hline
\end{tabular}

Revista Eletrônica de Estratégia \& Negócios, Florianópolis, v.7, n.3, set./dez. 2014. 


\begin{tabular}{|c|c|c|c|c|}
\hline & - Cultura. & & & \\
\hline Anhanguera & $\begin{array}{l}\text { Não foram apresentados } \\
\text { pelo entrevistados } \\
\text { recursos/capacidades com } \\
\text { essa característica }\end{array}$ & $\begin{array}{l}\text { Não foram } \\
\text { apresentados pelo } \\
\text { entrevistados } \\
\text { recursos/capacidades } \\
\text { com essa } \\
\text { característica }\end{array}$ & $\begin{array}{l}\text { - Tecnologia da } \\
\text { informação. }\end{array}$ & $\begin{array}{l}\text { - Capital aberto; } \\
\text { - Gestão; } \\
\text { - Economia de escala. }\end{array}$ \\
\hline Estácio de Sá & $\begin{array}{l}\text { - Gestão; } \\
\text { - Passivo trabalhista. }\end{array}$ & $\begin{array}{l}\text { - EAD; } \\
\text { - Padronização de } \\
\text { cursos; } \\
\text { - Gestão. }\end{array}$ & $\begin{array}{l}\text { - Equipe de gestores; } \\
\text { - Recursos Financeiros. }\end{array}$ & $\begin{array}{l}\text { - Captação de alunos; } \\
\text { - Economia de escala. }\end{array}$ \\
\hline PUC-MG & $\begin{array}{l}\text { - Folha de pagamento; } \\
\text { - Campi. }\end{array}$ & - Gestão. & - Localização. & $\begin{array}{l}\text { - Marca; } \\
\text { - Qualidade de ensino; } \\
\text { - Corpo docente. }\end{array}$ \\
\hline
\end{tabular}

Fonte: Elaborado pelos autores.

Nota: Para dados mais detalhados, consultar os resultados específicos de cada instituição na secção 4 do presente artigo.

\section{CONSIDERAÇÕES FINAIS}

O presente trabalho propôs-se a realizar um estudo da avaliação das capacidades e recursos estratégicos de sete instituições privadas de Ensino Superior, utilizando como referencia o modelo de Barney e Hesterly (2007), no sentido de se fornecer dados e informações não apenas para as instituições pesquisadas, como a todo o setor de educação superior privada no Brasil.

De acordo com o resultado da Análise de Conteúdo realizada com as entrevistas feitas junto aos executivos das empresas pesquisadas, pode-se evidenciar que os fatores do modelo VRIO (Valor, Raridade, Imitabilidade e Organização) estão presentes em praticamente todas elas, dando um sinal claro de intensa competição, algo que pode ser ampliado para todo seguimento.

O fator Desvantagem Competitiva apresentou algumas características inerentes das instituições pesquisadas, mas que podem servir para uma reflexão em todo o setor, sobretudo os que se mostraram congruentes em mais de uma instituição. Como, por exemplo, pode-se citar o fator de deficiência na gestão interna, uma vez que boa parte das instituições são geridas por acadêmicos que podem não estar familiarizados com regras de negócio, sobretudo em um mercado altamente competitivo. Outro fator de desvantagem 
observado é a pouca capacidade de investimento, pois os retornos financeiros, em alguns casos, são aquém do esperado. Investimento financeiro pode garantir maior divulgação da marca, contratação de corpo docente diferenciado e infraestrutura de ponta, que pode fazer a diferença nos resultados institucionais. Nota-se que esta desvantagem não aflige instituições com capital aberto na bolsa, o que sinaliza uma opção de estratégia para grupos educacionais que desejam captar mais recursos.

O fator Paridade Competitiva também carece de profunda reflexão englobando todo o setor. Uma vez que o mercado está saturado, a diferenciação será a saída para gerar um diferencial competitivo perante os concorrentes. Dentre os fatores de paridade, é interessante ressaltar a questão da infraestrutura, que é destacada em algumas das instituições pesquisadas. No geral, as instituições de Ensino Superior brasileiras tendem a seguir um mesmo padrão no que se refere à infraestrutura. Entretanto, modelos de salas de aula diferenciados têm se tornado uma constante nas principais universidades do mundo, o que pode individualizar uma instituição em um mercado, até então, pouco inovador. O mesmo vale para a grade curricular dos cursos, que deve obedecer uma legislação, mas pode ser inovada nas metodologias de ensino e aprendizagem.

O fator Vantagem Competitiva Temporária demonstrou que as instituições conseguiram atingir certos diferenciais, mas que podem ser alcançados pelos seus competidores. Dentre eles, é interessante uma reflexão na situação envolvendo a localização dos campi, uma vez que algumas regiões podem apresentar grande demanda reprimida, fazendo com que alguma instituição implante uma unidade visando a suprir esta demanda, e estes resultados influenciarem a implantação de outras instituições, acirrando a concorrência na região e pulverizando o mercado. É muito comum observar este tipo de prática em cidades que estão concentradas próximas às grandes capitais, nas chamadas regiões metropolitanas, devido à grande concentração de habitantes. Os cursos tecnológicos também foram citados como uma vantagem temporária, pois algumas instituições foram pioneiras na implantação e, com os resultados observados, outras passaram também a ofertá-los. Este cenário motiva a busca por uma nova modalidade da educação superior, sendo a Educação a Distância uma das modalidades mais exploradas pelas instituições privadas no momento. 
A Vantagem Competitiva Sustentável apresentou fatores que mostram o porquê das instituições de ensino e grupos educacionais estudados serem nacionalmente reconhecidas, a começar pelo fator marca, lembrado durante vários momentos. Em um cenário de intensa competição, em que o produto final é a educação, os principais compradores buscam a qualidade. Entretanto, na educação superior privada, o fator qualidade divide uma linha tênue com a força da marca, uma vez que o público alvo não consegue diferenciar, de maneira real, a qualidade das instituições disponíveis no mercado. Uma marca bem conceituada no mercado torna-se uma vantagem competitiva sustentável na medida em que irá trazer uma grande parcela do alunado, que servirá de uma retroalimentação para campanhas futuras. Não menos importante, vale a pena observar fatores como inteligência de negócios, gestão profissionalizada, gestão de Governança Corporativa em modelo matricial, dentre outras variáveis relacionadas à gestão. Isto sinaliza o bom resultado da gestão compartilhada, sobretudo dos grandes grupos educacionais, que trabalham em um modelo guarda-chuva, fornecendo às instituições participantes um modelo de gestão eficiente e padronizado.

Finalmente, pode-se verificar, com o respectivo estudo, que há uma tendência da formação e crescimento de grandes grupos educacionais, mas estes grupos também enfrentam vários desafios, possuindo desvantagens competitivas que devem ser observadas, sinalizando a necessidade de inovação no setor. Os dados coletados e tratados das entrevistas evidenciaram que a escolha das estratégias corretas representam um importante divisor de águas para se garantir o sucesso, em um cenário cada vez mais exigente e competitivo, listando uma série de características que podem ajudar na construção de um olhar difuso da educação superior privada no Brasil.

\section{REFERÊNCIAS}

AMIT, R.; SCHOEMAKER, P. J. H. Strategic assets and organizational rent. Strategic Management Journal, 14, n. 1, p. 33-45, 1993.

BAIN, J. S. Barriers to new competition. Cambridge, MA: Harvard, 1956.

BAIN, J. S. Industrial Organization. New York: John Wiley, 1959.

BARDIN, Laurence. Análise de Conteúdo. Lisboa: Edições 70, 2009. 
BARNEY, J. B. Firm resources and sustained competitive advantage. Journal of Management, v. 17, p. 99-120. 1991.

BARNEY, J. B. Loocking inside for competitive advantage. The Academy of Management Executive, Ada, v. 9, n.4, p. 49-61, nov. 1995.

BARNEY, J. B.; HESTERLY, W.S. Administração estratégica e vantagem competitiva. São Paulo: Pearson Prentice Hall, 2007.

DIERICKX, I., COOL, K. Asset Stock Accumulation and Sustainability of Competitive Advantage. Management Science, v. 35, n. 12, p. 1504-1511, dec. 1989.

GERMANO, J. W, Estado Militar e Educação no Brasil (1964-1985). São Paulo: Cortez Ed. Unicamp, 1993.

GEROSKI, P.A. Game Theory with Applications to Economics. International Journal of Industrial Organization, 6, n. 2, p. 155-281, 1988.

HAYES, R.H.; WHELLWRIGHT ,S.C.; and CLARK, K. Dynamic manufacturing: creating the learning organization. New York: The Free Press, 1988.

HOPER. Análise Setorial do Ensino Superior Privado-Brasil. Foz do Iguaçu, 2009.

INSTITUTO NACIONAL DE ESTUDOS E PESQUISAS EDUCACIONAIS ANÍSIO TEIXEIRA. Dados finais do Censo da Educação Superior 2011. Brasília: Instituto Nacional de Estudos e Pesquisas Educacionais Anísio Teixeira, 2012.

IWASSO, S.; CAFARDO, R. Procura diminui e particulares têm de enfrentar mudanças. 0 Estado de São Paulo, 17 out. 2005, p. A14.

IWASSO, S.; CAFARDO, R. Instituições buscam melhor gestão. O Estado de São Paulo, 15mar. 2007, p. A12.

LEARNED, E.; CHRISTENSEN, C.; ANDREWS, K.; GUTH, W. Bussiness policy: text and cases. Homewood, IL: R. Irwin, 1969.

MALHOTRA, N. Pesquisa de Marketing: uma orientação aplicada. Porto Alegre: Bookman, 2006.

MASON, E. S. Price and production policies of large scale enterprises. American Economic Review, v. 29, p. 61-74, 1939.

MASON, E. S. The current State of the Monopoly Problem in the U.S. Harvard Law Review, June, 1949.

MEYER JUNIOR, V. Planejamento Estratégico: Ato Racional, Político ou Simbólico: Um Estudo das Universidades Brasileira. In: ENCONTRO ANUAL DA ANPAD, 28., 2004, Curitiba, Anais... Curitiba: ANPAD, 2004. 
NELSON, R.R.; WINTER, S. G. An Evolutionary theory of economic change. Cambridge, MA: Harvard University Press, 1982.

PENROSE, E. T. The Theory of the Growth of the Firm. London: Basil Blackwell, 1959.

PENROSE, E. T. Teoria del crescimento de la empresa. Madrid: Aguilar, 1962.

PORTER, Michael E. Competitive Strategy. New York: Free Press, 1980.

PORTER, Michael E. Estratégia competitiva: técnicas para análise da indústria e da concorrência. Rio de Janeiro: Elsevier, 1986.

RUMELT, R.P. Towards a Strategic Theory of the Firm. Competitive strategic management. Englewood Cliffs, NJ: Prentice Hall, 1984.

SCHELLING, T.C. Strategy of conflict. Cambridge, MA: Harvard University Press, 1960.

SCHERER, F.M. Industrial market structure and economic performance. Boston: Houghton Mifflin, 1980.

SCHUMPETER, J. A. Capitalism, socialism and democracy. New York: Harper, 1942.

SHAPIRO, C. The theory of Business Strategy. Rand Journal of Economics, Spring, 1989.

TEECE, D. J. Economics of Scope and the Scope of an Enterprise. Journal of Economic Behavior an Organization, v. 1, p.223-247, 1980

TEECE, D. J. Towards an Economic Theory of the Mutiproduct Firm. Journal of Economic Behavior an Organization, v. 3, p. 39-63, 1982.

TEECE, D.J. Economic Analysis and Strategic Management. California Management Review, 26, n. 3, p. 87-110, spring, 1984.

TEECE, D.J. Technological Change and the Nature of the Firm. In G. Dosi et al.(Eds.), Technical Change and Economic Theory, 1988.

TEECE, D.J., PISANO, G., SHUEN, A. Firm capabilities, resources, and the concept of Strategy: Four Paradigms of Strategic Management. University of California at Berkeley: Free Press, 1990.

TEECE, D. J., PISANO, G., SHUEN, A. Dynamic capabilities and strategic management. Strategic Management Journal, vol. 18:7, p. 509-533, 1997.

YIN, R.K. Estudo de caso: planejamento e métodos. Porto Alegre: Bookman, 2005.

WERNEFELT, B. A Resource-Based View of the Firm. Strategic Management Journal, v. 5, p. 171-180, 1984.

WERNEFELT, B., MONTGOMERY, C. Tobin's $Q$ and the Importance of Focus in Firma Performance. American Economic Review, v. 78, n. 1, p. 246-250, 1988. 
ESTRATÉGIA E COMPETITIVIDADE: UM ESTUDO MULTICASO DA EDUCAÇÃO SUPERIOR PRIVADA BRASILEIRA

Ricardo Viana Carvalho de Paiva - Danilo de Melo Costa - Francisco Vidal Barbosa - Mário Teixeira Reis Neto

WILLIAMSON, O. E. Markets and Hierarchies. New York: Free Press, 1975.

WILLIAMSON, O. E. The Economic Institutions of Capitalism. New York: Free Press, 1985. 